\title{
Anesthetic drug propofol inhibits the expression of interleukin-6, interleukin-8 and cyclooxygenase-2, a potential mechanism for propofol in suppressing tumor development and metastasis
}

\author{
XUEFENG LI ${ }^{1}$, LONGYUN LI ${ }^{1}$, FENG LIANG ${ }^{1}$, GUIFENG LIU ${ }^{2}$ and GUOQING ZHAO ${ }^{1}$ \\ Departments of ${ }^{1}$ Anesthesiology and ${ }^{2}$ Radiology, China-Japan Union Hospital of Jilin University, \\ Changchun, Jilin 130033, P.R. China
}

Received September 11, 2015; Accepted May 11, 2017

DOI: $10.3892 / \mathrm{ol} .2018 .8515$

\begin{abstract}
Previous studies have indicated that anesthesia-associated drugs may directly inhibit cellular immunity and humoral immunity, which may be associated with tumor recurrence. The present study demonstrated that propofol may suppress the proliferation of MCF-7 cells and inhibit the expression of interleukin (IL)-6 and IL-8. Subsequent to treatment with propofol, MCF-7 cells demonstrated downregulated cyclooxygenase-2 (COX-2) protein expression and decreased levels of vascular endothelial growth factor and prostaglandin E2 in the supernatant. Therefore, the mechanism of propofol in suppressing tumor development and metastasis may be associated with the inhibition of IL-6, IL-8 and COX-2.
\end{abstract}

\section{Introduction}

At present, surgical resection serves as the preferred modality in cancer treatment, and cancer prognosis is largely dictated by the stage of tumor metastasis (1). However, despite surgery by an experienced surgeon, the diffusion of tumor cells into blood and lymph circulation is inevitable (2). It is accepted that tumor metastasis is determined by the metastatic ability of tumor cells, and anti-metastatic actions, such as surgical resection (3). Numerous previous studies have demonstrated that tumor metastasis is affected by various factors during surgery, including anesthesia (4), acute pain (5) and stress reactions (6).

Correspondence to: Dr Guoqing Zhao, Department of Anesthesiology, China-Japan Union Hospital of Jilin University, 126 Xiantai Street, Erdao, Changchun, Jilin 130033, P.R. China E-mail: ydysubmission@163.com

Dr Guifeng Liu, Department of Radiology, China-Japan Union Hospital of Jilin University, 126 Xiantai Street, Erdao, Changchun, Jilin 130033, P.R. China

E-mail: lgfsubmission@163.com

Key words: anesthesia drug, propofol, interleukin-6, interleukin-8, cyclooxygenase-2, antitumor mechanism
Among these factors, the effect of anesthetic drugs on tumor metastasis has attracted interest.

Certain previous studies $(7,8)$ have indicated that the drugs used in anesthesia may directly inhibit cellular and humoral immunity, which may be associated with tumor recurrence. However in other studies $(9,10)$, the effect of propofol treatment in suppressing the adhesion and metastasis of breast cancer cells was revealed. Melamed et al (11) compared the effects of different general anesthetics on tumor-bearing rats via intravenous injection. The results indicated that the number of tumor cells in the lungs of the rats was increased 5.5 and 2-folds in the rats of ketamine- and thiopentone-treated groups, respectively, but neither propofol nor diazepam treatment demonstrated these results. Nonetheless, the mechanism of propofol in the inhibition of tumor metastasis and proliferation remains unknown.

It is well established that angiogenesis serves a prerequisite role in cancer infiltration and metastasis, and that cyclooxygenase-2 (COX-2) overexpression is closely associated with angiogenesis in tumors (12). As the rate-limiting enzyme involved in the conversion of arachidonic acid into prostaglandin (PGs), COX-2 has been identified to be overexpressed in multiple tumors, including gastrointestinal, prostatic, lung and breast cancer (13-15). The meta-analysis of 90 studies conducted by Harris (16) indicated that regular administration of selective COX-2 inhibitors significantly reduced the incidence of colon, breast, lung and prostatic cancer. As breast cancer has been studied more extensively in recent years, the effects of COX-2 have been increasingly highlighted $(17,18)$. Animal experiments have demonstrated that the overexpression of COX-2 induced the genesis of breast cancer in transgenic mice (19). Selective inhibition of COX-2 effectively reduced tumorigenesis in rats (20), which indicates the direct involvement of COX-2 in the genesis of breast cancer.

In the present study, the inhibitory effects of two anesthetics, propofol and ketamine, on MCF-7 cells were compared and the effects of these two general anesthetics on cytokine production in mice bearing MCF-7 tumors were investigated.

\section{Materials and methods}

Reagents and antibodies. Propofol, ketamine, microculture tetrazolium (MTT) and celecoxib, which is a high selectively 
COX-2 inhibitor, used in the present study were analytically or chemically pure, and were purchased from Shanghai Sangon Biotechnology Co., Ltd. (Shanghai, China). The human breast cancer MCF-7 cell line was obtained from the American Type Culture Collection (Manassas, VA, USA). Fetal bovine serum (FBS) and RPMI-1640 medium were provided by Gibco, Thermo Fisher Scientific, Inc. (Waltham, MA, USA). The ELISA kit was purchased from Shanghai BlueGene Biotech Co., Ltd. (Shanghai, China). Rabbit anti-COX2 (catalog no. 10034) and mouse monoclonal anti-PGE2 antibody (catalog no. 18219) were purchased from Cayman Chemical Company (Ann Arbor, MI, USA) and were used as 1:300. The mouse anti- $\beta$-actin (catalog no. A1978, 1:2,000 dilution), the mouse monoclonal antibodies anti-VEGF (catalog no. V4758, 1:100 dilution) and the anti-rabbit horseradish peroxidase (catalog no. P7899, 1:100,000 dilution) were provided by Sigma-Aldrich; Merck KGaA (Darmstadt, Germany).

Cell culture and MTT assay. A 2x10 $/ \mathrm{ml} \mathrm{MCF-7} \mathrm{cell} \mathrm{suspen-}$ sion was prepared with RPMI-1640 culture medium containing $10 \%$ FBS, and was transferred to a 96-well plate with $100 \mu \mathrm{l}$ in each well. Then, the cells were incubated at $37^{\circ} \mathrm{C}$ with $5 \%$ $\mathrm{CO}_{2}$ for $24 \mathrm{~h}$ to obtain monolayer cells. Propofol, ketamine and celecoxib were diluted in RPMI-1640 medium containing $10 \%$ FBS to concentrations of 10, 20, 40, 60, 80, 100, 120, 140, 160 and $180 \mu \mathrm{mol} / \mathrm{l}$, and $100 \mu \mathrm{l}$ drug solution was added to each well. A total of 5 parallel wells were set for each, and the medium containing no drugs was added in the control group. Cell incubation for an additional $24 \mathrm{~h}$ was performed at $37^{\circ} \mathrm{C}$ with $5 \% \mathrm{CO}_{2}$. The culture medium was subsequently removed and, the cells were washed three times with cold PBS solution by centrifugation at $340 \mathrm{x}$ g for $5 \mathrm{~min}$ at room temperature. Following this, $180 \mu \mathrm{l}$ fresh culture medium and $20 \mu \mathrm{l}$ of MTT solution $(5 \mathrm{mg} / \mathrm{ml})$ were added to the cells and incubated at $37^{\circ} \mathrm{C}$ with $5 \% \mathrm{CO}_{2}$ for another $4 \mathrm{~h}$. The crystallization product was dissolved in $150 \mu \mathrm{l}$ dimethyl sulfoxide subsequent to the removal of the supernatant by centrifugation at $700 \mathrm{x} g$ for $10 \mathrm{~min}$ at room temperature, and the cell survival rate was calculated using the optical density (OD) value as determined by enzyme-linked analyzer (Omega Bio-Tek, Inc., Norcross, GA, USA) at $490 \mathrm{~nm}$. All test samples were assayed in quadruplicate, and cell viability was calculated using the following formula: Cell viability $=($ mean absorbance of test wells-mean absorbance of medium control wells)/(mean absorbance of untreated wells-mean absorbance of medium control well) x $100 \%$.

MCF-7 tumor-bearing nude mice model. All animal experiments were performed in accordance with the Animal Management Rules of the Ministry of Health of the People's Republic of China and the guidelines of the Animal Care and Use Committee of Jilin University (Changchun, China). Ethical approval was obtained from the Ethics Committee of the China-Japan Union Hospital of Jilin University. The nude mice were purchased from Experimental Animal Center of Changchun Biological Institute (Changchun, China), and kept under specific pathogen-free conditions. The room temperature was maintained at $27 \pm 1^{\circ} \mathrm{C}$ and the relative humidity was 40-60. The mice were fed three times a day and were exposed to $10 \mathrm{~h}$ light per day.
A total of 48 female BALB/c nude mice (18-20 g, 4-5 weeks old) were equally divided into two groups: A propofol treatment group and a ketamine treatment group. The mice in each group were additionally divided into three subgroups and a control group, and each mouse was inoculated with $5 \times 10^{6}$ living MCF-7 cells subcutaneously in the left axilla. The suspension of single MCF-7 cells was obtained following trypsin digestion of the cells in the exponential growth phase. Intra-peritoneal administration of the drugs at doses of 30, 60 and $80 \mathrm{mg} / \mathrm{kg}$ for each subgroup was performed subsequent to the diameter of tumor tissues reaching $0.5 \mathrm{~cm}$. After $4 \mathrm{~h}$ of propofol and ketamine administration, blood was collected through decapitation for $30 \mathrm{~min}$. Then, the levels of IL-1, IL-6, IL-8 and tumor necrosis factor (TNF)- $\alpha$ were determined using an ELISA kit according to the protocol of the manufacturer.

ELISA assay. MCF-7 cells in the logarithmic growth phase were obtained and seeded at $1 \sim 2 \times 10^{6}$ cells/well to a 6 -well plate. Cells were observed under a Leica DM6000B digital light microscope (Leica Microsystems, Wetzlar, Germany) at 200x magnification and viewed four fields (top left, bottom left, top right, bottom right). Then, the cells were incubated for $24 \mathrm{~h}$ at $37^{\circ} \mathrm{C}, 5 \% \mathrm{CO}_{2}$ and saturated humidity. The culture medium was changed after $24 \mathrm{~h}$, and then propofol and ketamine were added at final concentrations of $0,60,120$ and $180 \mu \mathrm{mol} / 1$. After a $24 \mathrm{~h}$-incubation at $37^{\circ} \mathrm{C}$, the culture medium was removed and the supernatant was collected by centrifugation at $700 \mathrm{x} \mathrm{g}$ for $10 \mathrm{~min}$ at room temperature following trypsin digestion. Then, $0.5 \mathrm{ml}$ supernatant by centrifugation at $700 \mathrm{x}$ g for $10 \mathrm{~min}$ was added into $0.1 \mathrm{ml} \mathrm{HCl}$, and the mixture was centrifuged at $700 \mathrm{x}$ g for $10 \mathrm{~min}$ at room temperature to obtain the supernatant. Following this, $0.1 \mathrm{ml} \mathrm{NaOH}$ was added to neutralize the acidulated sample. A total of $100 \mu \mathrm{l}$ standard substance or sample was added into the corresponding wells according to manufacturer's instructions. OD values at $490 \mathrm{~nm}$ were determined by using enzyme-linked analyzer (Omega Bio-Tek, Inc.), and zero adjustment was performed in the sample-free well, with 3 parallel wells set for each standard substance and sample. This experiment was repeated three times.

Western blot assay. MCF-7 cells in the logarithmic growth phase were obtained and seeded at a density of $1-2 \times 10^{6}$ cells/well into a 6-well plate. Then, the cells were incubated for $24 \mathrm{~h}$ at $37^{\circ} \mathrm{C}$ and $5 \% \mathrm{CO}_{2}$ and saturated humidity. The culture medium was changed after $24 \mathrm{~h}$, and then propofol, celecoxib and ketamine were added at final concentrations of $180 \mu \mathrm{mol} / 1$. Following $24 \mathrm{~h}$ incubation at $37^{\circ} \mathrm{C}$ with $5 \% \mathrm{CO}_{2}$, the culture medium was removed and the supernatant was collected by centrifugation at $700 \mathrm{x} \mathrm{g}$ for $5 \mathrm{~min}$ at room temperature following trypsin digestion. The cells were pelleted at $700 \mathrm{x} \mathrm{g}$ for $5 \mathrm{~min}$ at $4^{\circ} \mathrm{C}$ and lysed in $50 \mu \mathrm{l}$ cell lysis buffer $(20 \mathrm{mM}$ Tris, $\mathrm{pH} 7.4,100 \mathrm{mM} \mathrm{NaCl}, 1 \%$ Triton, $1 \mathrm{mM}$ phenylmethylsulfonyl fluoride, $10 \mu \mathrm{g} / \mathrm{ml}$ leupeptin, $10 \mu \mathrm{g} / \mathrm{ml}$ aprotinin). The protein concentration was determined by Bradford assay (Bio-Rad Laboratories, Inc., Hercules, CA, USA). Equivalent amounts $(50 \mu \mathrm{g})$ of protein were analyzed using 10\% SDS-PAGE gels. The gels were then electro-blotted onto polyvinylidene fluoride membranes. Following blocking with $5 \%$ milk at $37^{\circ} \mathrm{C}$ for $2 \mathrm{~h}$, membranes were incubated at $4^{\circ} \mathrm{C}$ with primary 


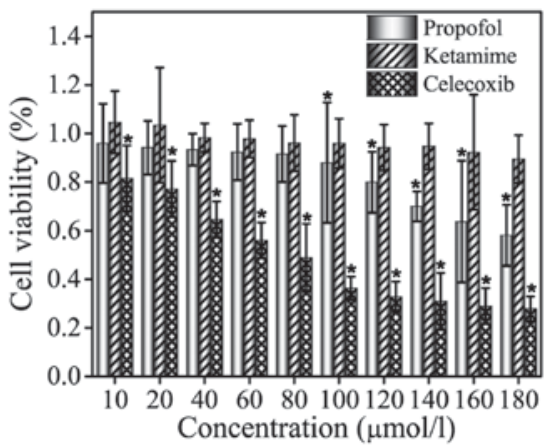

Figure 1. Inhibitory effects of propofol, ketamine and celecoxib treatment on MCF-7 cells as determined by MTT assay. Data are presented as the mean \pm standard deviation of experiments performed in triplicate. ${ }^{*} \mathrm{P}<0.05$ vs. ketamine group.

antibody overnight as described previously in the reagents and antibodies section. Finally, the relevant proteins were visualized following incubation with the appropriate secondary horseradish peroxidase-labeled antibody at $37^{\circ} \mathrm{C}$ for $1 \mathrm{~h}$ followed by visualization using enhanced chemiluminescent agent (Fuzhou Maixin Biotech Co., Ltd., Fuzhou, China). Densitometric scanning analysis was performed using ImageJ software version 1.62 (National Institutes of Health, Bethesda, MD, USA).

Statistical analysis. The experiments were performed in triplicate, and the data are presented as the mean \pm standard deviation. Data between $\geq 3$ groups were compared using one-way analysis of variance followed by a post-hoc test (Dunnett's test) using SPSS software package (version 13.0; SPSS, Inc., Chicago, IL, USA). $\mathrm{P}<0.05$ was considered to indicate a statistically significant difference.

\section{Results}

Inhibition of MCF-7 cells by propofol and ketamine treatment as determined by MTT assay. Celecoxib, propofol and ketamine were selected for MTT assay at screening concentrations of $10,20,40,60,80,100,120,140,160$ and $180 \mu \mathrm{mol} / 1$, and the results are shown in Fig. 1. As indicated in the figure, no significant inhibitory effect of ketamine treatment on cell viability was observed in MCF-7 cells. Compared with group ketamine, treatment with celecoxib exhibited a significant inhibitory effect on $\mathrm{MCF}-7$ cell viability $(\mathrm{P}<0.05)$. For propofol, the inhibition was not evident at low drug concentrations (10-80 $\mu \mathrm{mol} / \mathrm{l})$, whereas higher concentrations (100-180 $\mu \mathrm{mol} / \mathrm{l})$ exhibited an inhibitory effect that was weaker compared with celecoxib treatment. MCF-7 cells were inhibited by celecoxib and propofol treatment in a dose-dependent manner, and the cell survival rate decreased with increasing drug concentration. In summary, the results validated that ketamine does not exhibit an inhibitory effect on the proliferation of MCF-7 cells, and propofol inhibits MCF-7 cells in a dose-dependent manner with the efficient concentrations ranging between 100-180 $\mu \mathrm{mol} / 1$.

Analysis of changes in levels of cytokines in MCF-7 tumor-bearing mice by ELISA assay. Serum levels of IL-1,
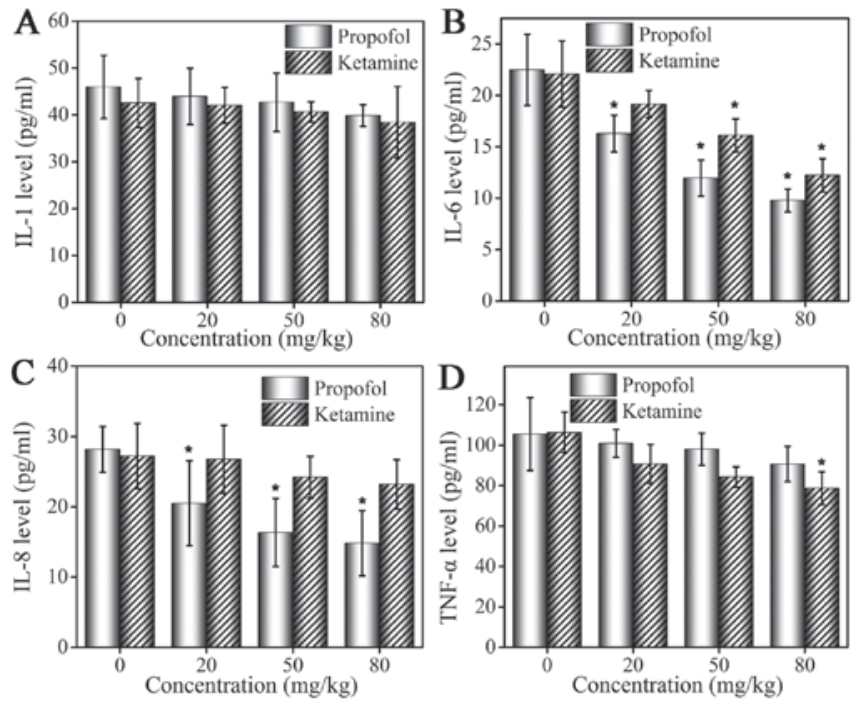

Figure 2. Changes in levels of cytokines in the sera of MCF-7 tumor-bearing mice following anesthesia. The changes in (A) IL-1, (B) IL-6, (C) IL-8 and (D) TNF- $\alpha$ levels in MCF-7 tumor-bearing mice treated with propofol and ketamine. Data are presented as the mean \pm standard deviation of experiments performed in triplicate. ${ }^{*} \mathrm{P}<0.05$ vs. untreated group. IL, interleukin; TNF, tumor necrosis factor.

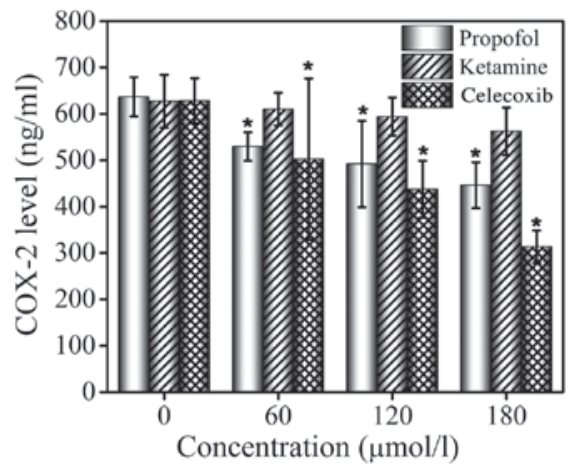

Figure 3. Inhibitory effects of propofol, ketamine and celecoxib treatment on COX-2 level in MCF-7 cells as determined by ELISA assay. Data are presented as the mean \pm standard deviation of experiments performed in triplicate. ${ }^{*} \mathrm{P}<0.05$ vs. untreated group. COX-2, cyclooxygenase- 2 .

IL-6, IL-8 and TNF- $\alpha$ following administration of propofol and ketamine are demonstrated in Fig. 2. At $4 \mathrm{~h}$ following anesthetic administration, serum cytokine levels were altered in the mice in the two groups. An ELISA assay was performed to detect levels of cytokines. Compared with the control group, mice treated with propofol and ketamine exhibited decreased serum levels of IL-1, but the inhibition was weak and no significant difference was observed (Fig. 2A). The level of IL- 6 was inhibited by propofol and ketamine, and a more marked inhibitory effect was observed with increased drug concentrations. In addition, propofol demonstrated a significantly stronger inhibition effect compared with that of ketamine (Fig. 2B). The level of IL- 8 was inhibited by propofol at a low concentration $(20 \mathrm{mg} / \mathrm{kg})$, while ketamine did not demonstrate a marked inhibitory effect on the level of IL-8 (Fig. 2C). The inhibition of TNF- $\alpha$ production was observed in the ketamine and propofol groups but at different levels. A marked inhibitory effect was observed in the 

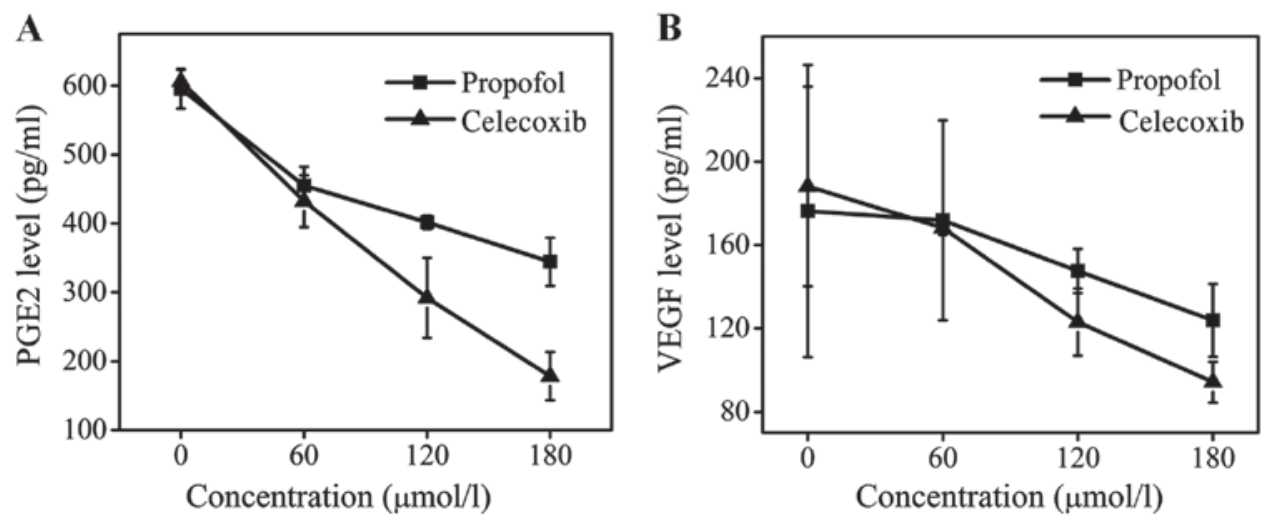

Figure 4. Level of (A) PGE2 and (B) VEGF expression in MCF-7 cells incubated with propofol and celecoxib for $24 \mathrm{~h}$ at $0,60,120$ and $180 \mu \mathrm{mol} / 1$ as determined by ELISA. Data are presented as the mean \pm standard deviation of experiments performed in triplicate. PGE2, prostaglandin E2; VEGF, vascular endothelial growth factor.
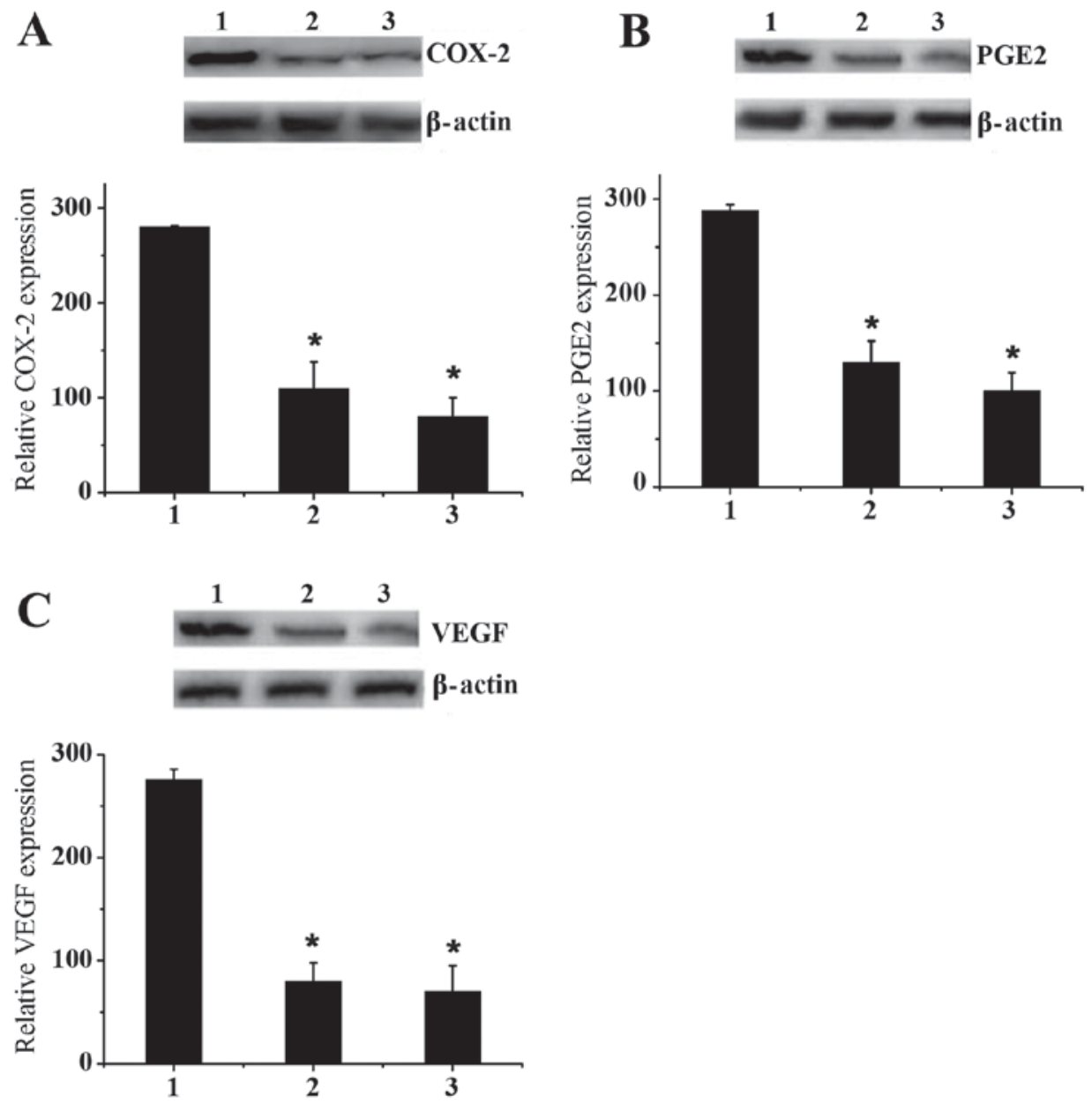

Figure 5. Western blot analysis. Level of (A) COX-2, (B) PGE2 and (C) VEGF expression in MCF-7 cells treated with ketamine, propofol and celecoxib at a dose of $180 \mu \mathrm{mol} / 1$. Data are presented as the mean \pm standard deviation of experiments performed in triplicate. ${ }^{*} \mathrm{P}<0.05$ vs. ketamine group. 1 , ketamine; 2 , propofol; 3, celecoxib; COX-2, cyclooxygenase-2; PGE2, prostaglandin E2; VEGF, vascular endothelial growth factor.

ketamine group, and a weaker inhibitory effect was observed in the propofol group (Fig. 2D).

Inhibitory effects of propofol and ketamine on COX-2 of MCF-7 cells determined by ELISA assay. ELISA assays were performed to determine the inhibition of COX-2 in MCF-7 cells by propofol, ketamine and celecoxib. Celecoxib, a known
COX-2 inhibitor, was used as the positive control. The ELISA assay results are presented in Fig. 3. It was demonstrated that ketamine treatment did not exhibit an inhibitory effect on COX-2 levels at concentrations $0,60,120$ or $180 \mu \mathrm{mol} / 1$, while celecoxib and propofol treatment significantly inhibited the production of COX-2 in a dose-dependent manner. It was identified that the release of COX-2 was effectively inhibited 
by propofol, even though this effect was less marked compared with that of celecoxib. The ELISA assay confirmed that the expression of COX-2 protein was significantly downregulated by propofol, but treatment with ketamine did not demonstrate this effect, indicating that the production of COX-2 may be inhibited by propofol.

Expression levels of PGE2 and VEGF in MCF-7 cells determined by ELISA and western blot assays. PGE2 is an important downstream protein of COX-2 and is involved in the promotion of tumor cell growth and angiogenesis (21-24). VEGF is also an important cytokine in the genesis and development of tumors (25). The levels of PEG2 and VEGF following celecoxib treatment were determined, and it was identified that celecoxib treatment may effectively downregulate the expression of PEG2 and VEGF (Fig. 4). At a dose of $180 \mu \mathrm{mol} / 1$, celecoxib reduced the concentration of PEG2 3-fold compared with the control group and decreased the level of VEGF to $100 \mathrm{pg} / \mathrm{ml}$, whereas the level of VEGF in the propofol group was $130 \mathrm{pg} / \mathrm{ml}$. The inhibitory effect of propofol treatment on the levels of PEG2 and VEGF was less marked compared with that of celecoxib, but remained evident. Compared with the control group, the levels of PGE2 and VEGF in the supernatant of MCF-7 cells was decreased following propofol treatment in a dose-dependent manner. Therefore, it may be concluded that the effect of propofol on tumor growth and development may be attributed to its ability to suppress the enzyme activity of COX-2 and inhibit the release of PGE2 and VEGF.

Western blot assays were performed to verify the ELISA assay results (Fig. 5). MCF-7 cells were cultured ex vivo in 6 -well plates with a dose of $180 \mu \mathrm{mol} / 1 \mathrm{ketamine}$, propofol and celecoxib. Fig. 5A indicated that propofol effectively downregulated the expression of COX-2 compared with ketamine, although this effect was less marked than with celecoxib. Similar results were observed for PGE2 and VEGF expression levels (Fig. 5B and C). These results effectively confirmed the previous conclusion drawn by ELISA assay.

\section{Discussion}

Propofol (2,6-diisopropylphenol) is one of a number of extensively used intravenous anesthetic agents that also exhibit antitumor effects (26,27). Propofol, at clinically relevant concentrations, may inhibit tumor invasion and result in apoptosis of human cancer cells (28). For example, Tsuchiya et al (29) demonstrated that propofol treatment may induce the apoptosis of human promyelocytic leukemia cells. Miao et al (30) has also shown that propofol is able to significantly decrease the invasive activity of human colon carcinoma cells. In animal studies $(31,32)$, propofol exerted antitumor activities by modulating immune reaction. However, it is unclear whether propofol exhibits inhibitory effects on tumor metastasis and proliferation. To the best of our knowledge, this is the first study investigating the mechanism of propofol in inhibiting MCF-7 tumor cell growth. It was demonstrated that propofol inhibited MCF-7 cells in a dose-dependent manner by inhibiting the expression of IL- 6 and IL- 8 and by downregulating COX-2 protein.
IL-6 is one of the cytokines with the most extensive range of functions. IL-6 facilitates the genesis and development of tumors primarily by regulating genes, which control cell cycle, accelerate tumor angiogenesis, promote local inflammatory response to tumor and enhance self-renewal of tumor stem cells (33). In the propofol treatment group, the serum level of IL-6 was lower compared with that of the ketamine treatment group, which may suggest a potential tumor inhibition mechanism of propofol.

It was also noted from the present study that the inhibitory effect of propofol treatment on the levels of IL- 8 was more marked compared with that of ketamine. This observation suggested that the different inhibitory effects of propofol and ketamine on tumor metastasis may be associated with differences in IL-8 levels. Singh et al (34) demonstrated the close interaction between IL- 8 and COX-2 in bone metastasis of breast cancer. The correlation between the expression of IL-8 and COX-2 in breast cancer has also been highlighted by numerous studies $(34,35)$, and it has been suggested that IL-8 and COX-2 are mutually regulated to promote the genesis and development of tumor (36). Therefore, the present study hypothesized that propofol may inhibit COX-2. The ELISA assay results confirmed that the production of COX-2 may be downregulated by propofol. As PGE2 is an important downstream protein of COX-2 that promotes tumor cell growth and angiogenesis, and VEGF is also an important cytokine in the genesis and development of tumors, the present study also investigated whether propofol exhibits inhibitory effects on PGE2 and VEGF expression by ELISA and western blot assays. The results confirmed the hypothesis.

In conclusion, the present study suggested that propofol may suppress the proliferation of MCF-7 cells and identified that propofol inhibited the expression of IL-6 and IL-8. Subsequent to treatment with propofol, downregulated COX-2 protein expression was observed in MCF-7 cells, and the levels of VEGF and PGE2 in the supernatant were also decreased. Therefore, a potential mechanism of propofol in inhibiting tumor development and metastasis is the inhibition of the expression of IL- 6 , IL- 8 and COX-2. The present study provides original data, and hypothesizes the antitumor mechanisms of propofol in MCF-7 cells. However, as the number of tumor samples and the tumor grade were limited, additional large-scale studies are required to explore the antitumor mechanism of propofol.

\section{Acknowledgements}

The authors would like to thank other members in Departments of Anesthesiology and Radiology, China-Japan Union Hospital of Jilin University for valuable suggestions and writing.

\section{References}

1. Jemal A, Siegel R, Ward E, Murray T, Xu J and Thun MJ: Cancer statistic, 2007. CA Cancer J Clin 57: 43-66, 2007.

2. Eschwège P, Dumas F, Blanchet $P$, Le Maire V, Benoit G, Jardin A, Lacour B and Loric S: Haematogenous dissemination of prostatic epithelial cells during radical prostatectomy. Lancet 346: 1528-1530, 1995.

3. Holmgren L, O'Reilly MS and Folkman J: Dormancy of micrometastases: Balanced proliferation and apoptosis in the presence of angiogenesis suppression. Nat Med 1: 149-153, 1995. 
4. Shapiro J, Jersky J, Katzav S, Feldman M and Segal S: Anesthetic drugs accelerate the progression of postoperative metastases of mouse tumors. J Clin Invest 68: 678-685, 1981.

5. Page GG, Blakely WP and Ben-Eliyahu S: Evidence that post-operative pain is a mediator of the tumor-promoting effects of surgery in rats. Pain 90: 191-199, 2001.

6. Ben-Eliyahu S: The price of anticancer intervention. Does surgery promote metastasis? Lancet Oncol 3: 578-579, 2002

7. Biki B, Mascha E, Moriarty DC, Fitzpatrick JM, Sessler DI and Buggy DJ: Anesthetic technique for radical prostatectomy surgery affects cancer recurrence: A retrospective analysis. Anesthesiology 109: 180-187, 2008

8. Tsui BC, Rashiq S, Schopflocher D, Murtha A, Broemling S, Pillay $\mathrm{J}$ and Finucane BT: Epidural anesthesia and cancer recurrence rates after radical prostatectomy. Can J Anaesth 57: 107-112, 2010

9. Forget P, Vandenhende J, Berliere M, Machiels JP, Nussbaum B, Legrand $\mathrm{C}$ and De Kock M: Do intraoperative analgesics influence breast cancer recurrence after mastectomy? A retrospective analysis. Anesth Analg 110: 1163-1635, 2010.

10. Chen X, Lu P, Chen L, Yang SJ, Shen HY, Yu DD, Zhang XH, Zhong SL, Zhao JH and Tang JH: Perioperative propofol-paravertebral anesthesia decreases the metastasis and progression of breast cancer. Tumour Biol 36: 8259-8266, 2015.

11. Melamed R, Bar-Yosef S, Shakhar G, Shakhar K and Ben-Eliyahu S: Suppression of natural killer cell activity and promotion of tumor metastasis by ketamine, thiopental, and halothane, but not by propofol: Mediating mechanisms and prophylactic measures. Anesth Analg 97: 1331-1339, 2003.

12. Kirkpatrick K, Ogunkolade W, Elkak A, Bustin S, Jenkins P, Ghilchik $M$ and Mokbel K: The mRNA expression of cyclo-oxygenase-2 (COX-2) and vascular endothelia growth factor (VEGF) in human breast cancer. Curr Med Res Opin 18: 237-241, 2002.

13. Chang SH, Liu CH, Conway R, Han DK, Nithipatikom K, Trifan OC, Lane TF and Hla T: Role of prostaglandin E2-dependent angiogenic switch in cyclooxygenase 2-induced breast cancer progression. Proc Natl Acad Sci USA 101: 591-596, 2004.

14. Simeone AM, Li YJ, Broemeling LD, Johnson MM, Tuna M and Tari AM: Cyclooxygenase-2 is essential for HER-2/neu to suppress $\mathrm{N}$-(4-hydroxyphenyl)retinamide apoptotic effects in breast cancer cells. Cancer Res 64: 1224-1228, 2004.

15. Barnes N, Haywood P, Flint P, Knox WF and Bundred NJ: Survivin expression in in situ and invasive breast cancer relates to COX-2 expression and DCIS recurrence. Br J Cancer 94 253-258, 2006

16. Harris RE: Cyclooxygenase-2 (cox-2) blockade in the chemoprevention of cancers of the colon, breast, prostate, and lung. Inflammopharmacology 17: 55-67, 2009.

17. Qin G, Xu F, Qin T,Zheng Q, Shi D, Xia W, Tian Y, Tang Y, Wang J, Xiao X, et al: Palbociclib inhibits epithelial-mesenchymal transition and metastasis in breast cancer via c-Jun/COX-2 signaling pathway. Oncotarget 6: 41794-41808, 2015.

18. Hugo HJ, Saunders C, Ramsay RG and Thompson EW: New insights on COX-2 in chronic inflammation driving breast cancer growth and metastasis. J Mammary Gland Biol Neoplasia 20: $109-119,2015$

19. Liu CH, Chang SH, Narko K, Trifan OC, Wu MT, Smith E, Haudenschild C, Lane TF and Hla T: Overexpression of cyclooxygenase-2 is sufficient to induce tumorigenesis in transgenic mice. J Biol Chem 267: 18563-18569, 2001.
20. Harris RE, Kasbari S and Farrar WB: Prospective study of nonsteroidal anti-inflammatory drugs and breast cancer. Oncol Rep 6: 71-73, 1999.

21. Joo YE, Rew JS, Seo YH, Choi SK, Kim YJ, Park CS and Kim SJ: Cyclooxygenase-2 overexpression correlates with vascular endothelial growth factor expression and tumor angiogenesis in gastric cancer. J Clin Gastroenterol 37: 28-33, 2003.

22. Wise H: Lack of interaction between prostaglandin E2 receptor subtypes in regulating adenylyl cyclase activity in cultured rat dorsal root ganglion cells. Eur J Pharmacol 535: 69-77, 2006.

23. Komuro M, Kamiyama M, Furuya Y, Takihana Y, Araki I and Takeda M: Gene and protein expression profiles of prostaglandin E2 receptor subtypes in the human corpus cavernosum. Int J Impot Res 18: 275-281, 2006.

24. Deasy BM, O'Sullivan-Coyne G, O'Donovan TR, McKenna SL and O'Sullivan GC: Cyclooxygenase-2 inhibitors demonstrate anti-proliferative effects in oesophageal cancer cells by prostaglandin E(2)-independent mechanisms. Cancer Lett 256: $246-258,2007$

25. Kellesarian SV, Al-Kheraif AA, Vohra F, Ghanem A, Malmstrom H, Romanos GE and Javed F: Cytokine profile in the synovial fluid of patients with temporomandibular joint disorders: A systematic review. Cytokine 77: 98-106, 2016.

26. Ren XF, Li WZ, Meng FY and Lin CF: Differential effects of propofol and isoflurane on the activation of T-helper cells in lung cancer patients. Anaesthesia 65: 478-482, 2010

27. Miyata T, Kodama T, Honma R, Nezu Y, Harada Y, Yogo T, Hara $\mathrm{Y}$ and Tagawa M: Influence of general anesthesia with isoflurane following propofol-induction on natural killer cell cytotoxic activities of peripheral blood lymphocytes in dogs. J Vet Med Sci 75: 917-921, 2013.

28. Mammoto T, Mukai M, Mammoto A, Yamanaka Y, Hayashi Y, Mashimo T, Kishi Y and Nakamura H: Intravenous anesthetic, propofol inhibits invasion of cancer cells. Cancer Lett 184: 165-170, 2002

29. Tsuchiya M, Asada A, Arita K, Utsumi T, Yoshida T, Sato EF, Utsumi $\mathrm{K}$ and Inoue $\mathrm{M}$ : Induction and mechanism of apoptotic cell death by propofol in HL-60 cells. Acta Anaesthesiol Scand 46: 1068-1074, 2002

30. Miao Y, Zhang Y, Wan H, Chen L and Wang F: GABA-receptor agonist, propofol inhibits invasion of colon carcinoma cells. Biomed Pharmacother 64: 583-588, 2010.

31. Kushida A, Inada T and Shingu K: Enhancement of antitumor immunity after propofol treatment in mice. Immunopharmacol Immunotoxicol 29: 477-486, 2007.

32. Inada T, Kubo K and Shingu K: Possible link between cyclooxygenase-inhibiting and antitumor properties of propofol. J Anesth 25: 569-575, 2011.

33. Tchirkov A, Khalil T, Chautard E, Mokhtari K, Véronèse L, Irthum B, Vago P, Kémény JL and Verrelle P: Interleukin-6 gene amplification and shortened survival in glioblastoma patients. $\mathrm{Br}$ J Cancer 96: 474-476, 2007.

34. Singh B, Berry JA, Vincent LE and Lucci A: Involvement of IL-8 in COX-2-mediated bone metastases from breast cancer. J Surg Res 134: 44-51, 2006.

35. Chou WY, Chuang KH, Sun D, Lee YH, Kao PH, Lin YY, Wang HW and Wu YL: Inhibition of PKC-Induced COX-2 and IL-8 expression in human breast cancer cells by glucosamine. J Cell Physiol 230: 2240-2251, 2015.

36. Simeone AM, Nieves-Alicea R, McMurtry VC, Colella S, Krahe R and Tari AM: Cyclooxygenase-2 uses the protein kinase C/interleukin-8/urokinase-type plasminogen activator pathway to increase the invasiveness of breast cancer cells. Int J Oncol 30: 785-792, 2007. 